\title{
Digital Technologies and Assets Management in Mining Companies
}

\author{
O. Yu. Lebedeva \\ Department of Economics, Accounting and Finance \\ Saint Petersburg Mining University \\ St. Petersburg, Russia \\ ole_spmi@mail.ru
}

\author{
V. V. Evseenko \\ Department of Economics, Accounting and Finance \\ Saint Petersburg Mining University \\ St. Petersburg, Russia
}

\begin{abstract}
The paper is aimed at revealing the potential of digital twin concept use in relation to mining companies' assets management. The key advantages of digital twin implementation in different areas of mining production have been summarized. Improved operation efficiency, production safety and informed decision-making process are among the top ones. The paper presents the conceptual model of digital twin of a deposit, which reflects both its structure and functioning mechanism. The idea of digital mineral asset underpins it in conjunction with tools of historical and real-time data collection, storage and analysis. The key issues of economic evaluation of mineral deposit digital twin are addressed.
\end{abstract}

Keywords: digital transformation, digital twin, digital mineral asset, digital dividends, mining companies, conceptual modelling

\section{INTRODUCTION}

Digital technologies have diverse application areas in industry due to advantages of processes optimization and benefits of effective information flows management. The improved production efficiency gained via operating costs reduction and increased productivity is ranked among the top benefits of industrial digitalization [1, 2]. It is worth noting that digital technologies have numerous applications both in manufacturing processes and business management, namely, in assets management. Although information systems and technologies are claimed not to provide direct benefits (but only create opportunities for their obtaining) [3], it is quite evident that qualitative changes in business processes of a company are associated with its improved key performance indexes. The digital twin concept has already brought revolution across some industry sectors. Recent scientific publications present a comprehensive sectoral analysis of digital twin application (in healthcare, education, construction, engineering, mining, transportation, sales, etc.) $[4,5,6,2]$. Currently, many companies use digital twins as simulation models only; however, academia and industry recognize the urgent task of their application as a technology of real-time control and management of physical objects [7]. Undoubtedly, it is necessary to explore and use the full potential of the digital twin concept in conditions of impetuous technological development (reduction in price of sensors, development of machine learning, artificial intelligence (AI), edge computing, cloud technologies) and increasing market needs for flexible production and its online controlling, as well as more efficient assets management [5].

The different aspects of the digital twin concept implementation are being investigated more intensively in relation to physical objects (units, devices and equipment) and production processes rather than with respect to such a complex system as mineral deposit or mineral asset.

In the current paper, we are aimed at justifying the potential of the digital twin concept application in management of mining companies' assets and describing the conceptual model of digital twin of mineral deposit

\section{METHODS}

The research objective was considered from the perspective of digital twin concept, first presented in 2000 by Dr. Grieves and well developed and refined for 20 years. Due to theoretical nature of the research, analysis of academic literature played the essential role within the research framework. It allowed us to conclude that most authors dealing with digital transformation research agree on the definition of the "digital twin": it is a virtual model of the process (the device, object or intangible asset), which reflects its characteristics over time, and gives the possibility to analyze the data and improve the efficiency of its work $[8,9]$.

The digital model consists of digitally represented physical, functional and other features of concrete object as a set of information saturated items (object prototype) [10]. A digital shadow (image) should be understood as a set of data about an object obtained simultaneously using special technologies [9]. There is still some confusion in the literature regarding the distinction between the concepts of digital twin and digital shadow, which are often identified the same [11, 12]. However, the main difference between digital twin and digital model (image or shadow) is the use of the best available technologies to reflect the dynamics of the physical 


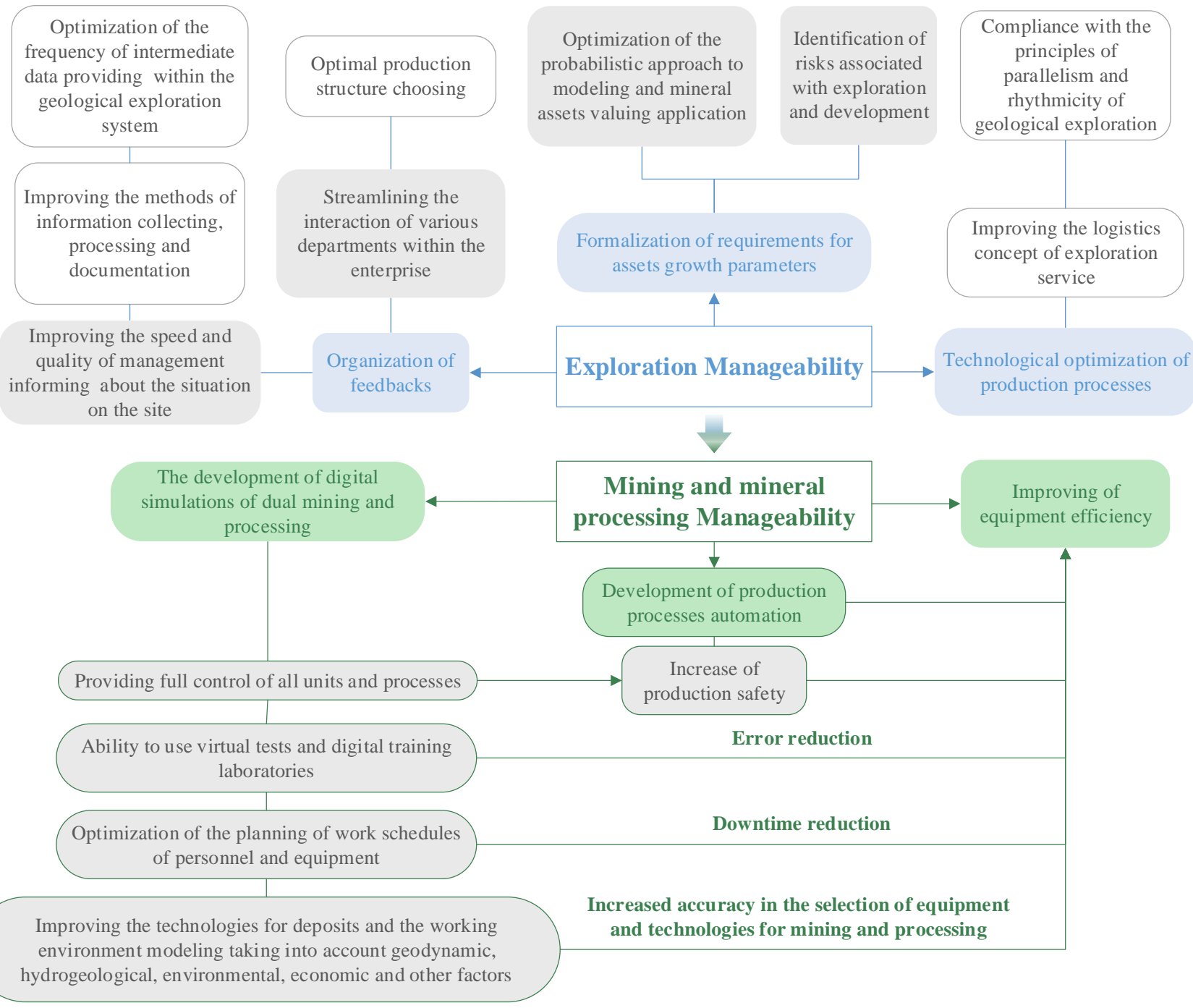

Fig. 1. Digitalization opportunities in terms of increased manageability of exploration and mining (Source: the authors)

twin through the associated data system, which ensures convergence between the physical and virtual space, as well as gives the ability to manage physical twin through the digital one [5]. Moreover, it is important to note that the digital model and digital shadow are parts of a digital twin; they do not have all of its characteristics without such a component as a digital stream (digital thread) [13]. Thus, the model of digital twin consists of three parts: physical object or process, its virtual copy and data thread connecting them in real time and providing requirements to a digital twin (scalability, interoperability and fidelity) $[14,7,4]$. Such methodical approach enabled us to reveal the areas of digital twin technology application relevant for mining companies and to describe the digital twin of a mineral deposit using conceptual modelling method.

\section{RESULTS}

"Patchwork digitalization" measures, being popular in mining sector over the past 10-15 years, prevented for a long time the transition of companies from the development of reliable projects with low profitability to qualitatively new assets that require investments in breakthrough digitalization technologies [15]. An overview of forecasts issued by the largest industry analytical agencies shows that the integrity, dynamism and complexity of decisions made should become the leitmotif of industry changes in the new decade [16]. The idea involves creating so-called "digital mines" (digital twin of the deposit) based on new mineral assets, where the digital transformation of production can be launched even at the stage of geological exploration.

Figure 1 shows the range of opportunities and challenges that innovative mining companies face at various stages of digital mine creation process. It should be pointed out that measures to attract breakthrough technologies of Industry 4.0 to the exploration, mining and processing provide an opportunity to influence almost all factors of their effectiveness.

So, automation technologies for robotic processes, which are already actively used in the industry today and are 


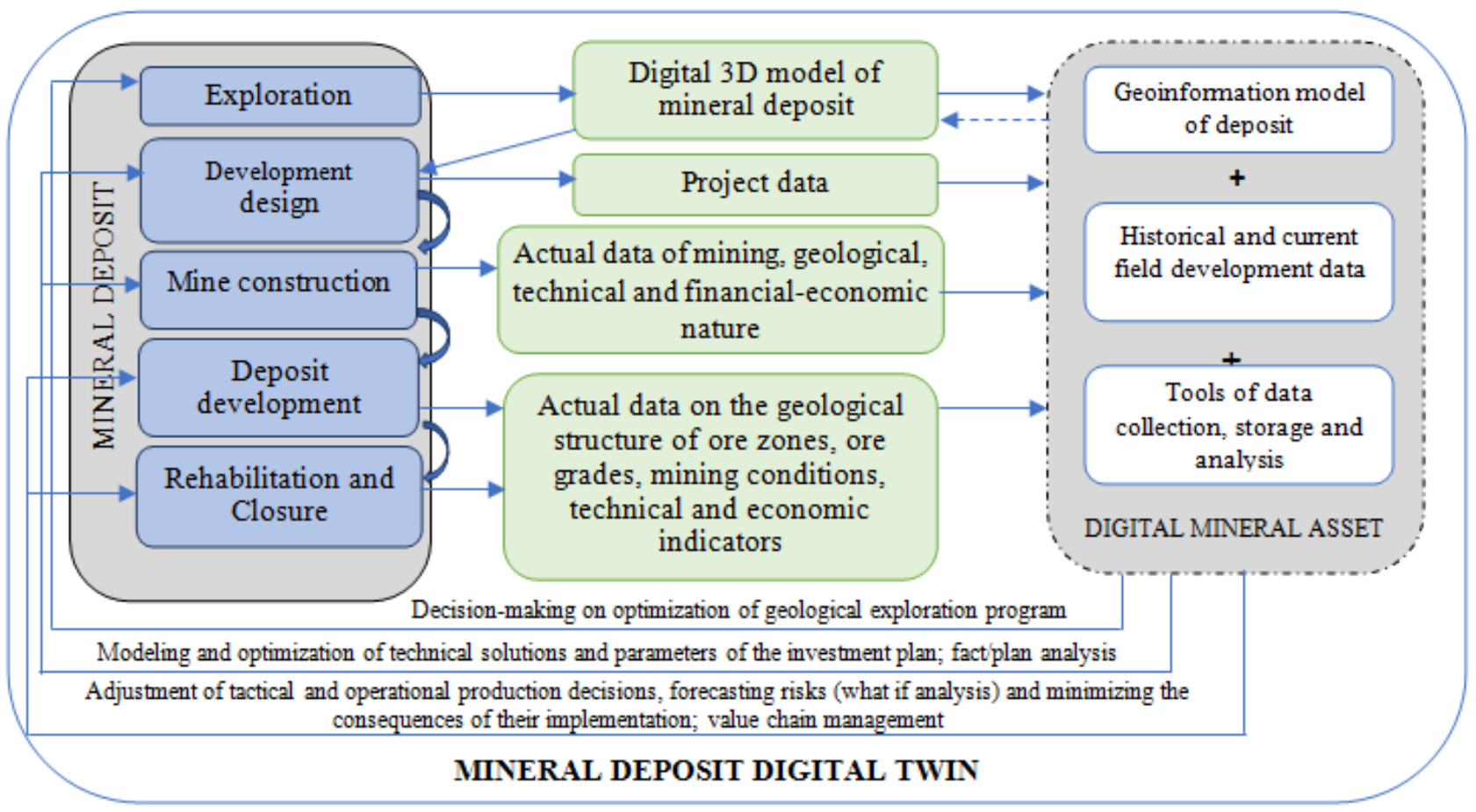

Fig. 2. Conceptual model of creation and functioning of mineral deposit digital twin (Source: the authors)

characterized by the initial level of AI systems maturity, allow to influence the factor of technological optimization of production processes. Augmented AI systems (2nd level of maturity) can be successfully applied in solving problems of information flows optimizing. In addition, such AI systems allow to use basic cognitive analytics tools to identify risks and provide simplify modeling. Mining companies leading in digital transformation of their activities are still striving to achieve precisely these goals [17].

At the same time, 3rd maturity level of AI systems, supposing full autonomy and deep machine learning, is not yet achieved in the mining and processing, however, in the future, it can provide significant time and cost savings in geological and financial modeling. Technologies of this level can allow making operational investment decisions, providing the necessary frequency of profitability and riskiness of investments matching, based on the most flexible planning system for exploration and mining.

Advantages of digital technologies represented in the diagram (Figure 1) should be assessed in align with mineral assets management concept, namely, digital mineral assets. This term is new and combines the features of a mineral and a digital asset.

There are different interpretations of a digital asset term in scientific literature. The most common of them broadly defines a digital asset as any digitized information that keeps value [18]. A comprehensive analysis of the "digital asset" concept from an economic and legal point of view is presented in papers of Kud A.A., founder and director of Simcord. The author, relying on the results of an etymological analysis, clarifies the concept of a digital asset taking into account its four essential semantic features: economic, legal, informational and valuable, defining the digital asset itself as a "set of digital (binary) data that is autonomous, uniquely identifiable and has a certain value" [19].

In manufacturing, the concept of a digital asset has its own nuances. Thus, specialists of the Neolant group of companies understand a digital asset as a combination of an information model of an object and an engineering data management system - a tool for updating information about an object at each stage of its life cycle, in which "all business processes that take place at the enterprise at the construction and exploitation stages are configured" [20]. In turn, the information model of an engineering object represents its digital (virtual) copy. A similar definition of a digital asset is used in AVEVA's business solutions: it is an information platform that is constantly replenished with real-time data as the state of a production facility changes and provides full integration and interaction of all applications in use [21]. Taking into account all the variety of existing definitions, we can distinguish common features of an object, recognized as a digital asset:

1. the asset exists in digital form and is a copy of a real object (unit, equipment, processing line, production complex, enterprise);

2. the digital copy of the object is "alive" and changes after the real object does;

3. the set of digitized data about the object brings/is able to bring the future economic benefits to the owner, e.g. by means of decision-making process automation. 
Mineral deposit digital twin concept goes align with the

Assuming asset is an economic entity, controlled by the company and capable of bringing business benefits throughout its life cycle period, it is reasonable to consider the mineral asset as reserves of mineral deposit that the company can develop effectively.

We suggest that the digital mineral asset should be defined as a virtual copy of the deposit, consisting of originally created geoinformation model, supplemented by geological, hydrodynamic and hydro- geological, technological, technical and economic data in the course of the field development, and serving as a basis for decision-making.

The digital mineral asset is a key component of mineral deposit digital twin (Figure 2). Its formation is carried out gradually, as the project of mineral deposit development passes through the phases of its lifecycle period. The proposed conceptual model of mineral deposit digital twin corresponds to the modern interpretations of the digital twin concept: its key elements are the mineral asset (deposit) itself, its information model (digital twin), the technical and information infrastructure needed for creating digital mineral asset, ensuring its identity to the real asset (deposit) and providing for informed decision making.

\section{DISCUSSION}

From an economic point of view, the mineral deposit digital twin satisfies such criteria of assets recognition as the ability to bring economic benefits, the presence of company's control over the asset and the ability to clearly identify it. Digital asset of a company is formed throughout the life cycle of the exploration and development investment project, but goes beyond it, because of ability to bring benefits after completion of mineral asset exploitation.

At the same time, the most important criterion for assets recognition is the possibility of their reliable valuation. The estimation of the value of a digital mineral asset is complicated. The concept itself is not yet recognized among academia due to its innovation character and the lack of widespread practice of mineral deposit digital twins creation. A digital mineral asset has a strong specificity: unlike most industries in which it is possible to repeatedly use digital twins, which mirror the standard equipment components, entire devices and even processes, a digital mineral asset is unique, like a real object, of which it is a virtual copy. Of course, this does not mean that the mineral deposit digital twin cannot be useful without reference to a specific asset. On the contrary, it can become a valuable information source for specialized scientific research in the field of deposits designing and development. However, this feature enhances ambiguous of the effectiveness estimation of digital solutions implementation in manufacturing and business processes of mining companies. "Digital dividends" as the benefits derived from the introduction of digital technology and enabling further development, have a time lag and are unevenly distributed [22]. From our point of view, the most difficult issue in justification of investments in digital twins is to estimate the value of the information that underpins the digital mineral asset, and to set the reasonable acceptable for the company criteria for making investment decisions. modern theory of the Asset Performance Management as a tool of proactive business planning, flexible and informed decision-making. In our opinion, the potential benefits of the digital twin use with regard to assets of mining company are the following:

1. obtaining direct economic benefits in the form of improved operational efficiency via reducing the cost of mining (loss in the subsoil, loss of time and other unproductive costs), the timing of the work, reducing the influence of the human factor when performing certain operations, optimizing investment costs of mine construction;

2. obtaining indirect benefits in the form of improved safety of the production via promptly taking into account risk factors when modeling possible negative events in real time as the field is developed and damage is prevented;

3. ensuring the flexibility of the managerial process by increasing the accuracy and validity of decisions made and the resulting learning effect (when performing exploration, design and construction works in the future).

In further research, we suppose to develop a detailed structure of the mineral deposit digital twin model, including description of its composition and mechanism of elements interaction, making a list of relevant data on the mineral asset, which should take into account the range of managerial tasks to be solved, and criteria for investment decision-making. Justification of the methodological approach to assessing the effectiveness of investments in mineral deposit digital twin is another important area for future research.

\section{References}

[1] A. Efremov, "Cifrovaya transformaciya v promishlennosti - globalyniy trend XXI veka”, Gornaya promishlennost, no. 4 (146), pp. 82-84, 2019.

[2] "Digital twin - Driving business value throughout the building life cycle", Siemens 2018 [Electronic resource]. Available at: https://assets.new.siemens.com/siemens/assets/ public.1562849283.610b5974-241d-4321-8ae6-55c6167446bf.bimdigitwin-ru.pdf.

[3] E.V. Vasilyeva and E.A. Deeva, "Metody expertnih ocenok v prikladnoy informacionnoy economike dlya obosnovaniya preimutschestv informacionnih system i tehnologiy", Mir novoy economiki, no. 4, 2017 [Electronic resource]. Available at: https://cyberleninka.ru/article/n/

metody-ekspertnyh-otsenok-v-prikladnoy-informatsionnoy-ekonomikedlya-obosnovaniya-preimuschestv-informatsionnyh-sistem-itehnologiy.

[4] M.J. Kaur, V.P. Mishra, and P. Maheshwari, "The Convergence of Digital Twin", IoT, and Machine Learning: Transforming Data into Action, In: M. Farsi, A. Daneshkhah, A. Hosseinian-Far, and H. Jahankhani (eds), Digital Twin Technologies and Smart Cities, Internet of Things, Technology, Communications and Computing. Springer, Cham, 2020.

[5] A. Rasheed, O. San, and T. Kvamsdal, "Digital Twin: Values, Challenges and Enablers", 2019 [Electronic resource]. Available at: https://arxiv.org/pdf/1910.01719.pdf. 
Y. Huang, H. Wu, H. Liu, Z. Yin (eds), Intelligent Robotics and Applications, ICIRA 2017, Lecture Notes in Computer Science, Springer, Cham, vol. 10464. 2017.

[15] PwC, Mine 2019: Resourcing the future, 2019 [Electronic resource]. Available at: https://www.pwc.com/gx/en/industries/energy-utilitiesresources/publications/mine.html.

[16] J. Basl, "Penetration of Industry 4.0 Principles into ERP Vendors' Products and Services - A Central European Study", A.M. Tjoa and et al. (Eds.): CONFENIS 2017, LNBIP 310, pp. 81-90, 2018. DOI: 10.1007/978-3-319-94845-4_8.

[17] Deloitte, Tracking the trends 2019: The top 10 issues transforming the future of mining, 2019 [Electronic resource]. Available at: https://www.deloitte.com/content/dam/Deloitte/us/ Documents/energy-resources/us-tracking-the-trends-2019.pdf.

[18] M. Averyanov, S. Evtushenko, and E. Kochetova, "Cifrovaya economika: noviye aktivy", 2016 [Electronic resource]. Available at: https://www.itweek.ru/digitalization/article/detail.php? $\mathrm{ID}=190477$.

[19] A.A. Kud, "Substantiation of the Term "Digital Asset": Economic and Legal Aspects", International Journal of Education and Science, 2 (1), pp. 41-52, 2019. DOI: 10.26697/ijes.2019.1.06.

[20] E. Consivar, "Cifroviye aktivy v cifrovoy economike", SAPR, Spesial Issue, pp. 2-7, 2018 [Electronic resource]. Available at: http://neolant.ru/upload/2018/27.11/1/Neolant.pdf.

[21] AVEVA, Cifrovoy aktiv [Electronic resource]. Available at: https://www.aveva.com/ru-RU/NewsEvents/Webinars/ /link.aspx?_id=67B8E3A1D8A647CF922A28F29B FF6FCB\&_z=z.

[22] World Bank Group, World Development Report 2016: Digital Dividends, Washington, DC: World Bank, 2016 [Electronic resource]. Available at: https://openknowledge.worldbank.org/ handle/10986/23347. License: CC BY 3.0 IGO.
[14] Q. Zhang, X. Zhang, W. Xu, A. Liu, Z. Zhou, and D.T. Pham, "Modeling of Digital Twin Workshop Based on Perception Data", In:

\author{
halle
}

